\title{
Relações Públicas: razões para praticá-las
}

\author{
Public Relations: reasons for practicing them
}

Relaciones Públicas: razones para practicarlas

\section{Maria Aparecida Ferrari}

- Doutora e mestre em Ciências da Comunicação pela Escola de Comunicações e Artes da Universidade de São Paulo (ECA-USP)

- Coordenadora do Curso de Relações Públicas da Universidade Metodista de São Paulo

- Professora dos programas de graduação e pós-graduação da ECA-USP.

- Membro da diretoria da Abrapcorp

- Autora, com James Grunig e Fábio França, do livro Relaçóes públicas: teoria, contexto e relacionamentos

- Autora de vários capítulos de livros e de artigos em revistas nacionais e internacionais

- maria.ferrari@metodista.br; maferrar@usp.br 
Este artigo procura refletir sobre as Relações Públicas como função gestora da Comunicação e seu papel na vida das organizações. Aborda-se a polêmica de as Relações Públicas serem ou não uma ciência ou uma arte, uma vez que sua definição continua sendo de difícil entendimento para muitos. Questiona ainda as diferenças da prática da atividade na América Latina e em países da Europa e da América do Norte. Aponta, por fim, uma contribuição para a legitimação da profissão que extrapola seu conceito como ciência e arte.

PALAVRA-CHAVE: RELAÇÕES PÚBLICAS • DEFINIÇÃO • PROFISSÃO • CORPUS DOCTRINAE • COMUNICAÇÃO

Abstract

This article discusses Public Relations as a communication management function and its roles in the organization. It questions whether Public Relations are a science or the practice of an art form, the fact that its definition is still difficult to comprehend, and discusses the problems that lead to the practical differences for its practice in Latin America, in the European nations and in North America. The article closes with a discussion of some of the major elements that legitimate a profession, going beyond its concept as a science or an art.

KEY WORDS: PUBLIC RELATIONS • DEFINITION • PROFESSION • CORPUS DOCTRINAE • COMMUNICATION

Resumen

Se busca reflexionar acerca de las Relaciones Públicas como una función gestora de la comunicación y sobre su papel en la vida de las organizaciones. Se aborda la polémica sobre la naturaleza de las Relaciones Públicas: si son o no una ciencia o un arte, ya que, para muchos, su definición sigue siendo difícil de entender. Se problematizan las diferencias de la práctica de la actividad en América Latina y en países de Europa y América del Norte. Y se finaliza con una contribución a la legitimación de la profesión, que extrapola su concepto como ciencia y arte.

PALABRAS CLAVE: RELACIONES PÚBLICAS • DEFINICIÓN • PROFESIÓN • CORPUS DOCTRINAE • COMUNICACIÓN 
Está presente nas justificativas de quase todos os acadêmicos e profissionais brasileiros que as Relações Públicas não "deslancharam" ou não se "legitimaram" como outras atividades da área da Comunicação porque seu problema básico está na falta de uma clara definição de sua própria identidade.

\section{Relações Públicas, ciência ou não?}

Andrade (1983, p. 33) já dizia que, "apesar da notável literatura sobre a matéria - principalmente nos Estados Unidos, Brasil, Grã-Bretanha e França - e o amplo desenvolvimento que as Relações Públicas vêm alcançando em várias partes do globo terrestre, o sentido da expressão ainda não está em fase de cristalização". O mesmo autor (1993, p. 29) também afirmou que "há tantas definições e conceitos sobre relações públicas quanto há estudiosos, professores, profissionais e admiradores dessa atividade".

Nos Estados Unidos as definições que surgiram ao longo dos anos foram assimiladas pela sociedade, diferentemente do que ocorreu no Brasil e nos demais países latino-americanos. Uma série de definições foram criadas pela academia e aceitas pela sociedade como a de Cutlip, Center e Broom (2000, p. 4), que dizem: "Relações públicas constituem uma função de direção que estabelece e mantêm relações mutuamente benéficas entre uma organização e os públicos dos quais depende seu êxito ou fracasso". Outra definição contemporânea é a de Grunig e Hunt (1984, p. 4), que consideram "as Relações Públicas a administração da comunicação entre uma organização e seus públicos”.

No Brasil, na década de 1980, Porto Simões (1995, p. 42) apresentou uma teoria sustentada por um conjunto lógico de deduções e definiu as Relações Públicas como "o exercício da administração da função política organizacional, enfocado através do processo de comunicação da organização com seus públicos”. Em sua obra, o autor considerava as Relações Públicas uma ciência, abarcando "o conhecimento científico que explica, prevê e controla o exercício de poder no sistema organização-públicos” (1995, p. 33). Entre os pesquisadores brasileiros, Porto Simões foi o único a apresentar uma teoria das Relações Públicas baseada na teoria da função organizacional política, uma vez que para o autor as Relações Públicas se constituem em uma atividade científica que tem como objeto os conflitos entre os públicos e as organizações.

Ao lado de Porto Simões, as demais definições são classificadas como descritivas, funcionais e operacionais (França, 2003), limitando-se à exposição de técnicas e de propriedades midiáticas e no "como-fazer" e não no "ser" da atividade. Ter uma definição que seja clara e compreensível também passa pela questão de saber se estamos tratando das Relações Públicas como uma ciência, uma disciplina ou ainda, como afirmam outros, uma arte. Essa situação, apresentada sem nenhuma fundamentação teórica, colabora ainda mais para que as Relações Públicas sejam pouco entendidas tanto no contexto empresarial 
como na sociedade como um todo, principalmente na América Latina, conforme estudos desenvolvidos por Ferrari (2000).

Mas, afinal, as Relações Públicas são uma ciência ou uma arte? Se a atividade for considerada ciência, ela deve possuir um corpo teórico próprio, articulado de forma a indicar com segurança a seus seguidores como se portar em casos específicos, prevendo os resultados desse comportamento. Se a encararmos como arte, temos que entendê-la como uma habilidade baseada na intuição.

Não obstante o esforço que muitos acadêmicos latino-americanos têm feito com suas pesquisas, ainda nos falta uma clara definição que seja aceita pela categoria e que tenha objetividade para a sociedade. O exercício se complica quando observamos que em outros países a formação específica em Relações Públicas e os requisitos para o seu exercício não dependem de regulamentação ou de conselhos profissionais com função fiscalizadora. É o caso dos Estados Unidos e de vários países da Europa, onde é possível encontrar profissionais que obedecem a certos critérios profissionais, enquanto outros praticam a função sem a observância dos aspectos considerados necessários pelas associações da categoria, e em ambos os casos os profissionais têm a competência e as habilidades necessárias para praticar a atividade.

Se considerarmos as Relações Públicas como profissão, é necessário que essa atividade se paute por critérios precisos e aplicáveis de maneira efetiva em benefício das organizações e da sociedade. Para Cutlip, Center e Broom (1985), é importante que exista uma formação especializada, baseada em teorias e pesquisas, com ênfase no conhecimento muito mais do que nas habilidades; que a prática profissional tenha como resultado a produção de um serviço ou produto que seja essencial para a sociedade; que a prática esteja baseada no bem-estar da sociedade e na responsabilidade social; que exista autonomia no exercício profissional com responsabilidade individual e transparência; que a prática esteja balizada por um código de ética e por critérios de performance. Nesse sentido, Grunig e Hunt (1984) completaram afirmando que o profissionalismo nas Relações Públicas seria alcançado quando os profissionais colocassem em prática um conjunto de valores profissionais; fossem membros de uma associação profissional reconhecida pela sociedade e que lhes garanta a aderência às normas profissionais; e, acrescente-se, quando existissem nesse cenário uma tradição intelectual associada ao estabelecimento de um corpo de conhecimentos e habilidades técnicas adquiridas por meio de uma educação profissionalizante.

É curioso observar que, em países nos quais a prática das Relações Públicas não implica na existência de um registro profissional e/ ou de um curso específico, se observam critérios e paradigmas mais altos de profissionalismo do que nos países em que existe a obrigatoriedade do diploma superior de Relações Públicas e também do registro profissional. Se verificarmos o que ocorre no Brasil, onde há mais de quarenta anos predomina uma lei que criou a profissão e um conselho que a fiscaliza, detectamos que a profissão não alcançou eleva- 
dos níveis teóricos e práticos e que seu conceito não se legitimou na sociedade por causa da proteção legal.

Diante dessa constatação, fica claro que é necessário um corpo teórico de conhecimentos, ou seja, na linguagem acadêmica, um corpus doctrinae que sustente sua existência e possa orientar em um único sentido o exercício profissional dessa atividade. Como se observa na América do Norte e na Europa, o domínio desse conhecimento não depende necessariamente da formação específica no curso superior de Relações Públicas, uma vez que os profissionais têm praticado a atividade de forma objetiva, eficaz e constante. Ledingham e Bruning (apud VAN RULLER; VERCIC, 2003, p. 161) complementam afirmando que

a Comunicação é a base de sustentação das Relações Públicas e que a Comunicação é um fundamento necessário, porém, insuficiente para as Relações Públicas. A capacitação em Psicologia Social, Antropologia e outras Ciências Sociais, para não mencionar as novas tecnologias, é necessária ao lado da capacitação em Administração, Marketing e até, talvez, algumas capacitações específicas de certas áreas da indústria.

Tal arcabouço de conhecimentos só é possível ser atingido por meio da educação continuada, da capacitação permanente nas áreas citadas e afins e na experiência adquirida no decorrer da vida profissional, pois para exercer o papel estratégico da atividade de Relações Públicas, além da visão aberta de mundo, são necessários anos de experiência acumulada.

Esse tema é assunto para vários debates e reflexões, porém, neste artigo essa retomada conceitual foi feita para embasar e justificar se podemos continuar a dizer que as Relações Públicas são realmente necessárias ao desempenho organizacional e, se sim, como podem ser definidas de modo a serem aceitas pela sociedade?

Nossa próxima tarefa é defender por que as Relações Públicas são tão importantes para uma organização como as demais funções que colaboram para o seu desenvolvimento e indicar que elementos devem fazer parte de seu corpus doctrinae para legitimar o seu exercício e lhes atribuir a mesma importância que têm os demais setores que compõem a estrutura organizacional.

Elementos que contribuem para a constituição do corpus doctrinae e a legitimação do exercício das Relações Públicas

\section{Analisar cenários}

A análise de cenários é a etapa na qual o profissional de relações públicas examina o ambiente interno e externo, as oportunidades e ameaças que possam vir a 
afetar uma organização, assim como os chamados assuntos emergentes (issues management) que eventualmente envolvam a vida organizacional. Quanto mais o profissional conhecer o ambiente da organização, identificar as tendências a serem atendidas, for capaz de classificar os públicos da organização por ordem de importância e compreender a cultura organizacional, mais fácil lhe será escolher estratégias para conseguir o cumprimento dos objetivos organizacionais. Na medida em que o profissional analisa os elementos constitutivos da organização e desenha as estratégias para alcançar os objetivos definidos pela alta direção, mais aumenta a possibilidade de reforçar os seus valores. É na sua função de "analista de cenários" que o relações-públicas dará sentido ao seu trabalho e encontrará sustentação para tornar as Relações Públicas mais bem compreendidas. Dessa forma cumprirá sua missão de colaborar com a alta administração no estabelecimento das diretrizes que conduzirão suas ações para realizar sua missão e promover o espírito empreendedor das pessoas que com ela colaboram para a consecução de seus objetivos.

\section{Tratar de maneira coerente os relacionamentos}

Ao realizar a análise de cenários, o profissional de relações públicas sente-se preparado para identificar, classificar os públicos de interesse da organização e verificar quais são suas necessidades e expectativas. A visão contemporânea de Relações Públicas reforça a importância dos relacionamentos com os públicos para a existência e permanência das organizações no seu ambiente. Relacionamento pode ser considerado como uma série de interações de interdependência entre duas ou mais partes. Ele é intrinsecamente dialógico e, portanto, o profissional de relações públicas deve conhecer as características de cada um dos públicos estratégicos da organização para se relacionar de forma efetiva com cada um deles. Por outro lado, o relacionamento propicia uma identificação dos públicos para com a organização. Esse é um dos pontos-chave do trabalho de Relações Públicas: conhecer as expectativas dos públicos para adequar o formato dos relacionamentos com cada um deles.

\section{Buscar a simetria entre as partes}

A simetria significa diálogo, consenso e mediação. Ela não é perfeita, mas é o espaço no qual se equilibram forças e é assim que as organizações funcionam, produzindo sentidos e trocando expectativas. A verdadeira simetria que o profissional de relações públicas deve buscar na comunicação da organização está baseada no seu conhecimento sobre ela, sua história, trajetória, seus heróis, suas crenças, seus valores, ou seja, é a cultura da empresa que transparece por meio de suas ações e seus comportamentos diante de seus públicos. Quando a organização reconhece que sua missão é interagir e dar vida ao propósito estabelecido pelos seus membros, a comunicação é o processo que facilitará o seu entendimento e a sua razão de ser. 
A riqueza das empresas não está mais relacionada à posse de terrenos, bens materiais, mas sim está nos valores “intangíveis”, como marca, reputação, cultura corporativa, capital intelectual, relacionamentos com públicos, sustentabilidade, entre outros (DOMENEGHETTI; MEIR, 2009). Os profissionais de relações públicas sempre tiveram como função ajudar as organizações a definir sua identidade e verificar a percepção e sua reputação por meio de seus públicos estratégicos. Portanto, apesar de não ser novidade para o profissional, é importante e necessário que a alta administração passe a considerar os fatores "intangíveis" como os valores pelos quais se estabelecem as diferenças da organização diante de suas concorrentes. Tal é a força dos intangíveis que o Banco Nacional de Desenvolvimento Social (BNDES), a partir de 2008, passou a avaliar também os ativos intangíveis como critério essencial para a liberação de empréstimos para as empresas brasileiras. Assim, quesitos como capacidade de inovação, relacionamento com stakeholders, reputação, marca, riscos ambientais inerentes ao negócio responderão por pelo menos $50 \%$ do peso da avaliação que o banco fará da companhia que solicitou o empréstimo.

\section{Diminuir a possibilidade de crises}

Quando o profissional de relações públicas analisa os cenários, identifica os públicos estratégicos e dá tratamento diferenciado a cada um deles, age em sintonia com o modelo de gestão organizacional e estabelece simetria no processo comunicacional, pode-se dizer que trabalha de forma a diminuir o risco do surgimento de crises e situações de emergência. Segundo Grunig (2003), existem quatro princípios que devem ser praticados antes e durante a comunicação de crises. O primeiro, do relacionamento, diz que as organizações se tornam menos vulneráveis às crises e a questões emergentes quando estabelecem relacionamentos duradouros com os públicos que podem ser afetados por ela ou vice-versa. O segundo, da responsabilidade, aponta que as organizações devem aceitar a responsabilidade de administrar uma crise até mesmo quando não sejam causadoras delas. O terceiro, da transparência, se refere à postura objetiva, clara e rápida de informar sobre todos os fatos que ocorrem no momento da crise. E, por último, o princípio da comunicação simétrica, assume que os interesses dos públicos são tão relevantes quanto os da organização.

\section{Considerações finais}

Julgamos que a questão aqui levantada é tema para vários outros artigos, uma vez que concluímos que a regulamentação e a fiscalização da profissão por conselhos autárquicos não têm representado um diferencial no comportamento dos profissionais que praticam as Relações Públicas no mercado latinoamericano. A formação na área e a assimilação de conhecimentos específicos são essenciais para poder colocar em prática os cinco fatores apresentados na 
segunda parte do artigo. Não obstante, nos encontramos em um momento bastante especial, no qual os acadêmicos têm um papel fundamental para o futuro da profissão ao levantar as verdadeiras bases da atividade. A definição de um corpus doctrinae não significa que essa atividade deva estar visceralmente ligada a uma legislação. Deve sim estar conceitualmente definida em termos específicos, reconhecidos pela academia e pela sociedade. Concluindo, as Relações Públicas são uma função gerencial ou uma prestação de serviços às organizações e à sociedade, enquanto a comunicação é um processo e um instrumento das Relações Públicas na medida em que possibilita a interação planejada e permanente com os públicos.

\section{Referências}

ANDRADE, C. Teobaldo de Sousa. Para entender relações públicas. 3. edição. São Paulo, Loyola, 1983.

CUTLIP, Scott M.; CENTER, Allen H.; BROOM, Glenn M. Effective public relations. 8. ed. Englewood Cliffs, NJ: Prentice Hall, 2000.

. Effective public relations. $5^{\text {th }}$ ed. Englewood Cliffs, NJ: Prentice Hall, 1985.

DOMENEGHETTI, Daniel; MEIR, Roberto. Ativos intangíveis: o real valor das empresas. 2. ed. Rio de Janeiro: Campus, 2009.

FERRARI, Maria Aparecida. A influência dos valores organizacionais na determinação da prática e do papel dos profissionais de relações públicas: estudo comparativo entre organizações do Brasil e do Chile. São Paulo, 2000. Tese (Doutorado em Ciências da Comunicação) - ECA-USP.

FRANÇA, Fábio. Subsídios para o estudo do conceito de relações públicas no Brasil. Comunicação e Sociedade, São Bernardo do Campo, PósCom-Metodista, a. 24, n. 39, p. 127-154, 1. sem. 2003.

GRUNIG, James E. A função das relações públicas na administração e sua contribuição para a efetividade social e organizacional. Comunicação \& Sociedade, São Bernardo do Campo, PósCom-Metodista, a. 24, n. 39, p. 67-92, 1. sem. 2003.

GRUNIG, James E.; HUNT, Todd Managing public relations. Orlando, CA: Holt, Rinehart and Wisnton, 1984.

SIMÕES, R. Porto. Relações públicas: função política. 5. ed. São Paulo, Summus, 1995.

VAN RULER, Betteke; VERCIC, Dejan. Relações públicas na Europa: uma visão dos pesquisadores de Bled. Comunicação \& Sociedade, São Bernardo do Campo, PósCom-Metodista, a. 24, n. 39, p. 155-172. 1. sem. 2003. 